\title{
TOLERÂNCIA À DESSECAÇÃO DE SEMENTES DE CAFEEIRO (Coffea arabica L. ${ }^{1}$
}

\author{
DELACYR DA SILVA BRANDÃO JUNIOR², MARIA DAS GRAÇAS GUIMARÃES CARVALHO VIEIRA ${ }^{3}$, \\ RENATO MENDES GUIMARÃES ${ }^{3}$, HENK W.M. HILHORST ${ }^{4}$
}

\begin{abstract}
RESUMO - A aquisição da tolerância à dessecação pode ocorrer durante o desenvolvimento das sementes de diversas espécies. Entretanto, para sementes de cafeeiro, os resultados apresentados pela literatura ainda não são conclusivos. A presente pesquisa foi desenvolvida com os objetivos de verificar em que estádio de desenvolvimento sementes de Coffea arabica adquirem tolerância à dessecação e o efeito imediato e ao longo do armazenamento e da secagem na viabilidade e no vigor destas sementes. Foram utilizadas sementes de cafeeiro da cultivar Acaiá Cerrado colhidas nos estádios verde (chumbão), verde cana e cereja. Uma amostra das sementes não foi submetida à secagem (controle) e outra foi secada em estufa de circulação forçada, regulada à temperatura constante de $30^{\circ} \mathrm{C}$, até atingir grau de umidade de $15 \%$. Posteriormente, as sementes foram acondicionadas em recipientes de vidro de $200 \mathrm{~mL}$ hermeticamente fechados e mantidos em câmara à temperatura de $10^{\circ} \mathrm{C}$ e $50 \%$ UR. As avaliações foram efetuadas aos zero, 3, 6 e 9 meses de armazenamento, sendo avaliado o grau de umidade, a qualidade fisiológica, por meio dos testes de germinação, protrusão radicular, percentagem de raízes secundárias, emergência em câmara de crescimento e índice de velocidade de emergência. De acordo com os resultados, sementes de cafeeiro apresentam elevação do nível de tolerância à dessecação à medida em que se desenvolvem. Sementes secadas a $15 \%$ de umidade mantêm a qualidade fisiológica ao longo de nove meses de armazenamento sob condições de $10^{\circ} \mathrm{C}$ e $50 \%$ de UR e embalagem hermética, enquanto as não secadas (50\% de umidade) apresentam queda linear ao longo do armazenamento.
\end{abstract}

Termos para indexação: café, semente, tolerância à dessecação, maturação, secagem, armazenamento.

\section{DESICCATION TOLERANCE IN COFFEE SEEDS (Coffea arabica L.)}

\begin{abstract}
Desiccation tolerance acquisition is a phenomenon which may occur during the development of seeds of several species, but it has been little investigated for coffee seeds. The present research was carried out to ascertain at which stage of coffee seed development tolerance to desiccation is acquired. Seeds of Coffea arabica cultivar Acaiá Cerrado harvested at three maturation stages, green, yellow and reddish were used. Part of the seeds was dried in forced air, under constant temperature of $30^{\circ} \mathrm{C}$ until the seed moisture content reached $15 \%$. Then the seeds were stored in hermetic containers in a cool chamber at $10^{\circ} \mathrm{C}$ and $50 \%$ relative humidity. The evaluation was made after zero, 3, 6 and 9 months of storage, looking at moisture content, physiological conditions through the germination test, radical protrusion, percentage of secondary roots, emergence in growth room, emergence speed index. According to the results it was possible to conclude that coffee seeds present an increased desiccation tolerance as they reach later development stages. Seeds harvested at the green and yellow stages presented a decline in the production of secondary roots and percentage of seedling emergence. Drying seeds to $15 \%$ moisture content provided conditions to keep physiological quality throughout 9 months storage
\end{abstract}

\footnotetext{
${ }^{1}$ Aceito para publicação em 19/07/2002; parte integrante da Tese de Doutorado do primeiro autor, na Área de Fitotecnia da UFLA - MG. Desenvolvido com recursos da CAPES.

${ }^{2}$ Eng $^{\mathrm{o}} \mathrm{Agr}^{\mathrm{o}}$, Dr., Prof. Visitante do Depto. de Biologia, UFLA; Cx. Postal 37,37200-000, Lavras, MG; e-mail: dbrandao@ufla.br
}

\footnotetext{
${ }^{3}$ Eng $^{\circ}$ Agr $^{\circ}$, Dr., Prof. do Depto. de Agricultura, UFLA; e-mail: mariagcv@ufla.br; renatomg@ufla.br

${ }^{4}$ Dr. Wageningen University and Research Centre (WUR), Holanda; e-mail: henk.hilhors@pph.dpw.wau.nl
} 
at $10^{\circ} \mathrm{C}$ and $50 \%$ relative humidity. Non dried seeds (50\% moisture content) presented a linear reduction in the physiological quality when stored at $10^{\circ} \mathrm{C}, 50 \%$ relative humidity in hermetic containers.

Index terms: coffee, seed, desiccation tolerance, maturation, drying, storage.

\section{INTRODUÇÃO}

A habilidade de as sementes ortodoxas tolerarem a dessecação é adquirida progressivamente durante o desenvolvimento, antes que as sementes sofram uma severa queda no seu conteúdo de água. Porém, não se pode afirmar se a tolerância é adquirida antes ou em resposta à perda de água (Bewley \& Black, 1985; Leprince et al., 1993). Existem sementes que apresentam uma rápida transição de uma fase de intolerância à tolerância à dessecação, enquanto outras (recalcitrantes) não podem resistir à dessecação, devendo seu conteúdo de água permanecer alto durante todo o seu desenvolvimento e armazenamento. Além disso, algumas sementes recalcitrantes, de origem tropical, também são susceptíveis à injúria por resfriamento, ocorrendo morte de sementes, na faixa de temperatura de 10 a $15^{\circ} \mathrm{C}(\mathrm{Chin}, 1988)$. Alguns autores classificaram as sementes de cafeeiro (C. arabica L.) como recalcitrante (Roberts, 1973; King \& Roberts, 1979), contudo, após alguns anos, foi sugerido que as sementes de cafeeiro não eram verdadeiramente recalcitrantes e poderiam ser ortodoxas (Roberts et al., 1984). Ellis et al. (1990) sugeriram uma categoria intermediária para sementes de cafeeiro, onde estas possam resistir à desidratação até um certo grau de umidade, mas têm sua armazenabilidade reduzida.

Em determinados estádios de desenvolvimento específicos as sementes tornam-se tolerantes à dessecação, após passarem por um estado de intolerância, para diversas espécies. Para sementes de cafeeiro os resultados apresentados pela literatura variam em função das diferentes espécies do gênero Coffea. Ellis et al. (1991) verificaram que sementes de $C$. arabica oriundas de frutos de maturidade intermediária (verde cana) foram mais tolerantes à dessecação, do que as colhidas no estádio cereja (frutos maduros) ou no estádio verde (imaturos). Já Carvalho \& Alvarenga (1979) observaram que a germinação de sementes oriundas de frutos maduros foi muito superior a de frutos imaturos ou de maturidade intermediária. Guimarães (2000) detectou que o vigor das sementes de cafeeiro aumentou sensivelmente na fase de desenvolvimento entre os estádios verde e verde cana.

A presente pesquisa foi realizada com os objetivos de verificar em que estádio de desenvolvimento sementes de
Coffea arabica L. adquirem tolerância à dessecação e o efeito imediato e ao longo do armazenamento e da secagem na viabilidade e no vigor das sementes.

\section{MATERIAL E MÉTODOS}

O presente estudo foi realizado no Laboratório de Análise e Biotecnologia de Sementes da Universidade Federal de Lavras (MG). Foram utilizadas sementes de cafeeiro (Coffea arabica L.), cultivar Acaiá Cerrado, colhidas em campos de produção de sementes da universidade.

A colheita e despolpamento dos frutos nos estádios verde (chumbão), verde cana e cereja foram efetuados manualmente. Após despolpados os frutos foram degomados por submersão em água à temperatura constante de $30^{\circ} \mathrm{C}$, durante o período de 24 horas. Em seguida, as sementes foram lavadas em água corrente e colocadas sobre papel-toalha para retirada do excesso de água. Uma amostra das sementes não foi submetida à secagem (controle) e a outra foi secada em estufa com circulação forçada de ar, regulada à temperatura constante de $30^{\circ} \mathrm{C}$, até as sementes atingirem o grau de umidade de $15 \%$ (base úmida). Posteriormente, as sementes foram acondicionadas em recipientes de vidro de $200 \mathrm{~mL}$ com tampa, lacradas hermeticamente e armazenadas em câmara fria à temperatura de $10^{\circ} \mathrm{C}$ e $50 \% \mathrm{UR}$.

As avaliações das sementes foram efetuadas no início (zero) e após 3, 6 e 9 meses de armazenamento, quanto ao grau de umidade e à qualidade fisiológica, por meio dos testes de germinação, protrusão radicular, percentagem de raízes secundárias, emergência em câmara de crescimento e índice de velocidade de emergência.

A determinação do grau de umidade foi realizada pelo método da estufa a $105^{\circ} \pm 3^{\circ} \mathrm{C}$, durante 24 horas, utilizando duas repetições para cada tratamento, conforme prescrições das Regras para Análise de Sementes (Brasil, 1992). Os resultados foram expressos em percentagem (base úmida).

O teste de geminação foi realizado com quatro subamostras de 50 sementes para cada uma das quatro repetições dos tratamentos. O endocarpo da semente foi removido antes da semeadura, que foi realizada em papel toalha no sistema rolo, umedecido com água na quantidade de 2,5 vezes o peso 
do papel. Os rolos, contendo as sementes, foram mantidos em germinador regulado à temperatura constante de $30^{\circ} \mathrm{C}$. As avaliações foram feitas após 15 dias (protrusão de radícula) e 30 dias do início do teste, computando-se as plântulas normais. Foram consideradas plântulas normais, aquelas que apresentavam radícula e hipocótilo com comprimento superior a dois centímetros e se encontravam aparentemente sadias. Resultados expressos em percentagem.

A percentagem de plântulas com raízes secundárias foi efetuada conjuntamente com o teste de germinação, em que foram computadas, aos 30 dias após a semeadura, as plântulas que apresentavam raízes secundárias. Os resultados foram expressos em percentagem.

A emergência sob condições de câmara de crescimento foi conduzida em bandejas, contendo uma mistura de areia + terra na proporção de 2:1. Foram utilizadas quatro subamostras de 50 sementes/repetição semeadas a uma profundidade de 3 $\mathrm{cm}$. As bandejas foram dispostas inteiramente casualizadas em câmara de crescimento regulada à temperatura constante de $30^{\circ} \mathrm{C}$, em regime alternado de luz e escuro de 12 horas. No decorrer do teste foram realizadas regas quando necessárias. A emergência foi determinada com contagem única das plântulas emergidas, aos 60 dias após a semeadura. Foram consideradas emergidas plântulas que apresentavam os cotilédones acima do substrato. Os resultados foram expressos em percentagem.

$\mathrm{O}$ índice de velocidade de emergência foi conduzido conjuntamente com o de emergência. A velocidade de emergência foi determinada anotando-se diariamente o número de plântulas com mais de dois centímetros de comprimento, até a completa estabilização do estande. O índice de velocidade de emergência foi estabelecido segundo os critérios adotados por Maguirre (1962).

O delineamento utilizado foi o inteiramente casualizado, em esquema fatorial $(3 \times 2 \times 4)$ com quatro repetições, sendo 3 estádios de desenvolvimento (verde, verde cana e cereja), 2 teores de água (sementes não secadas e secadas até $15 \%$ de umidade) e 4 períodos de armazenamento (zero, 3, 6 e 9 meses). Os dados percentuais foram transformados em arc. sen $\sqrt{x / 100}$, sendo realizada análise de variância para todas as características analisadas.

Para comparação das médias de estádio de desenvolvimento e dos efeitos da secagem foi utilizado o teste de Tukey, a 5\% de probabilidade, enquanto que para comparação das épocas de avaliação foi empregado análise de regressão polinomial.

\section{RESULTADOS E DISCUSSÃO}

Pelos resultados dos testes determinantes da qualidade fisiológica, conduzidos anteriormente no armazenamento, pode ser verificado (Figuras 1 a 3) que a qualidade fisiológica das sementes colhidas no estádio verde e não secadas (controle) foi inferior a daquelas colhidas no estádio verde cana e cereja, que por sua vez não diferiram significativamente entre si. Esses resultados contrastam com os obtidos por Carvalho e Alvarenga (1979) que detectaram valores percentuais de germinação inferiores nas sementes de cafeeiro colhidas no estádio verde (chumbinho) e verde cana, em relação às colhidas no estádio cereja.

Nas Figuras 1 a 3 observam-se reduções percentuais significativas quando as sementes colhidas no estádio verde fo-

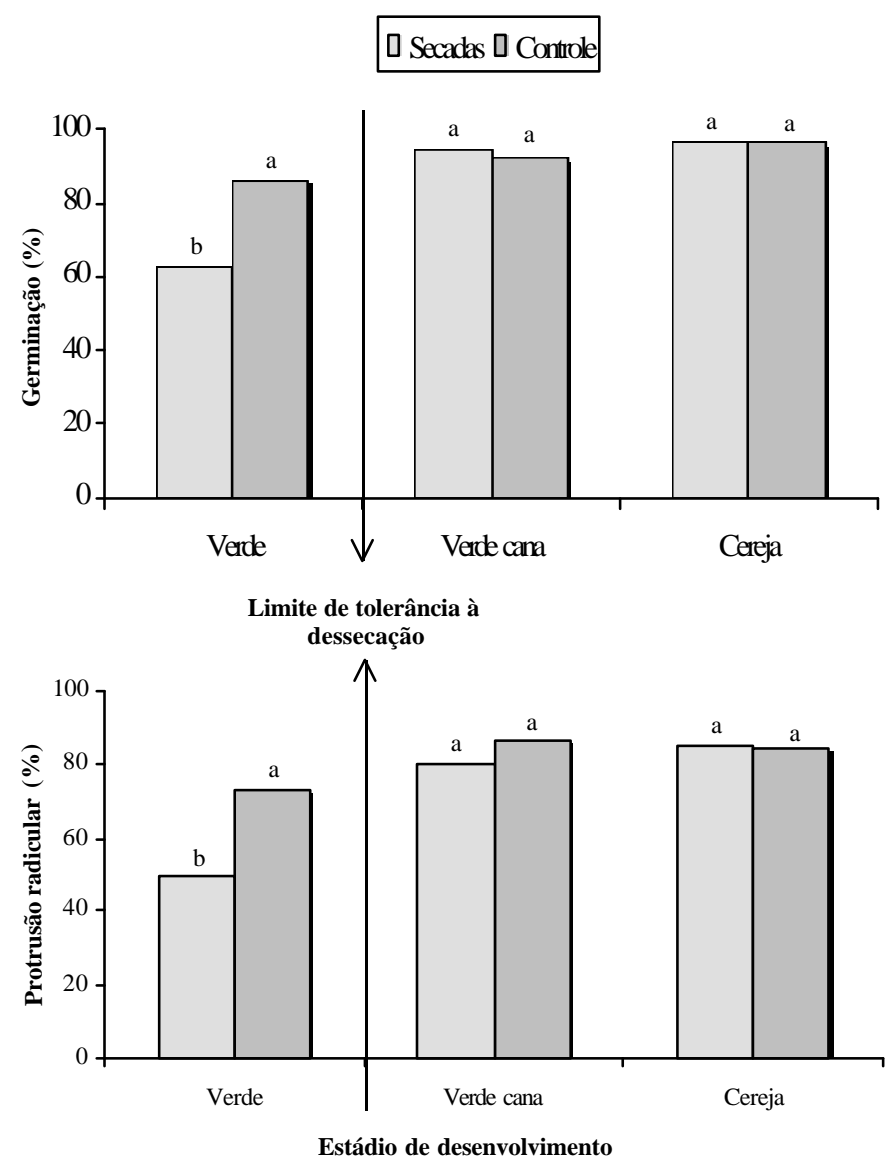

FIG. 1. Efeito da secagem na germinação e protrusão radicular de sementes de cafeeiro colhidas em diferentes estádios de desenvolvimento.

Médias seguidas de mesmas letras minúscula (coluna), dentro de cada parâmetro, não diferem entre si pelo teste de Tukey $(\mathrm{p}<0,05)$. 


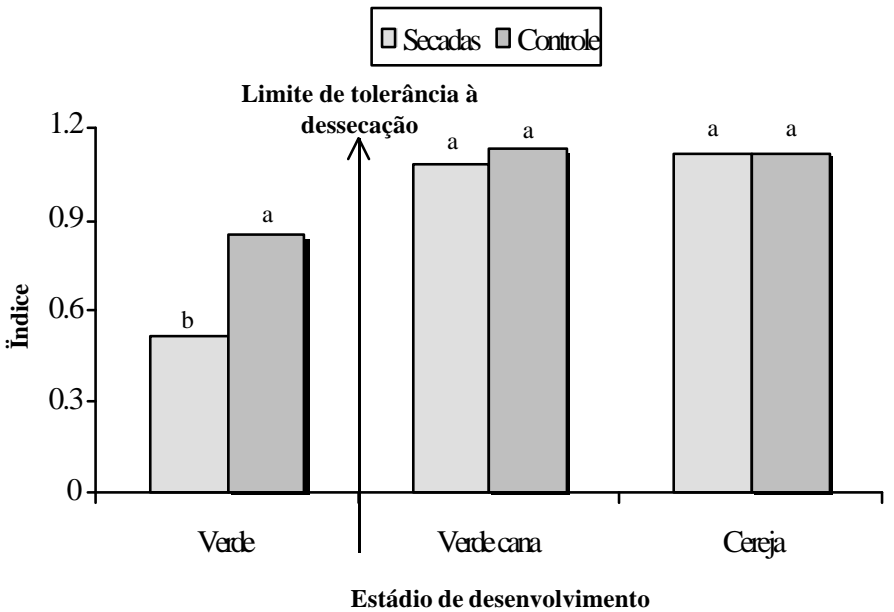

FIG. 2. Efeito da secagem no índice de velocidade de emergência de sementes de cafeeiro colhidas em diferentes estádios de desenvolvimento.

Médias seguidas de mesmas letras minúscula (coluna), dentro de cada parâmetro, não diferem entre si pelo teste de Tukey $(\mathrm{p}<0,05)$.

ram secadas para $15 \%$ de umidade. Por outro lado, apenas os testes de emissão de raízes secundárias e emergência em câmara de crescimento detectaram diferenças significativas do efeito da secagem sobre a qualidade fisiológica das sementes colhidas no estádio verde cana e não foi detectada diferença significativa para efeito de secagem nas sementes colhidas no estádio cereja (Figura 3). Esses resultados sugerem que sementes de $C$. arabica L., colhidas no estádio verde não toleram a dessecação e que, entre o estádio verde e verde cana, adquirem certa tolerância à dessecação, tornando-se mais tolerante no estádio cereja. Diversos autores (Bochicchio et al., 1993, 1994, 1996; Brenac et al., 1997) verificaram que embriões frescos de sementes de milho germinam mesmo em estádios precoces de desenvolvimento, quando eles ainda são intolerantes à dessecação, e que em estádios tardios do desenvolvimento, quando já adquiriram tolerância à dessecação, a secagem induz a um desvio do desenvolvimento inicial para a germinação.

De uma maneira geral, pode ser observado que sementes colhidas nos estádios verde cana e cereja apresentaram melhor condição fisiológica que aquelas colhidas no estádio verde, ao passo que os testes de emissão de raízes secundárias e emergência em câmara de crescimento detectaram ser a semente colhida no estádio cereja significativamente mais tolerante à dessecação que as colhidas no estádio verde cana, seguidas das colhidas no estádio verde (Figura 3). Araújo et al. (1989) também não verificaram efeito imediato da secagem nas temperaturas de 30 e $40^{\circ} \mathrm{C}$ sobre a qualidade das

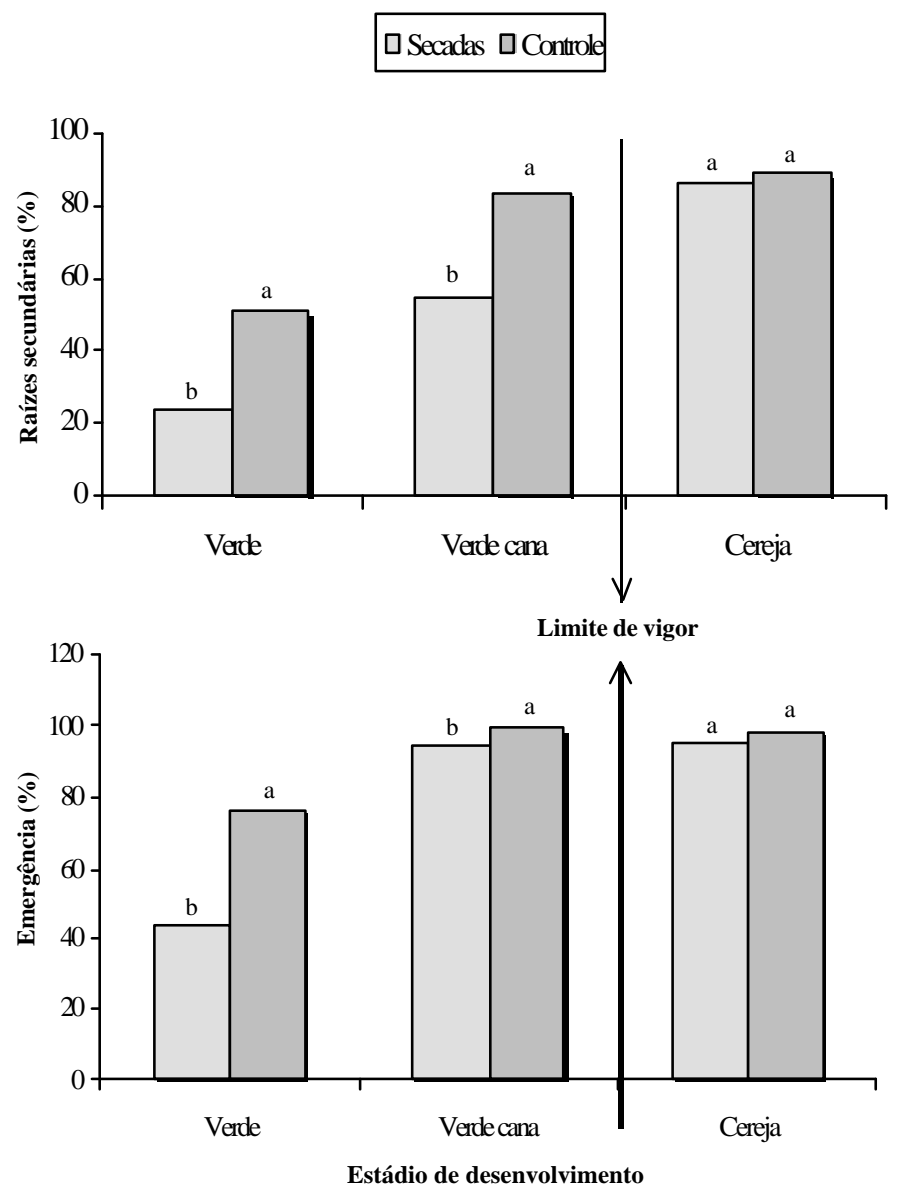

FIG. 3. Efeito da secagem na emissão de raízes secundárias e emergência de sementes de cafeeiro colhidas em diferentes estádios de desenvolvimento.

Médias seguidas de mesmas letras minúscula (coluna), dentro de cada parâmetro, não diferem entre si pelo teste de Tukey $(\mathrm{p}<0,05)$.

sementes oriundas de frutos colhidos no estádio cereja. O efeito deletério da secagem só foi verificado após o período de seis meses de armazenamento sob condições de ambiente de laboratório.

Apesar de as sementes não secadas apresentarem, inicialmente, valores de germinação, protrusão radicular e percentagem de raízes secundárias superiores aos das sementes secadas, independente do estádio de desenvolvimento, estas apresentaram tendência de queda linear ao longo do armazenamento (Figuras 4 a 6), ao passo que sementes secadas a $15 \%$ de umidade não apresentaram essa tendência. Provavelmente, isso foi devido ao alto metabolismo das sementes armazenadas com $50 \%$ de umidade (não secadas), em recipiente impermeável, o que pode resultar em várias mudanças bioquímicas e metabólicas que levam à deterioração das sementes (Copeland e McDonald, 1995; Priestley, 1986). Sementes 
$\begin{array}{llll}\text { yvu }=53,6215-6,91848 x & r^{2}=0,8956 & \text { yvcs }=63,6537+4,50678 x-0,55498 x^{2} & r^{2}=0,9951 \\ \text { yvs }=45,7385-1,16747 x & r^{2}=0,9000 & \text { ycu }=75,8890-9,10921 x & R=0,7638\end{array}$

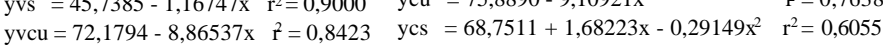

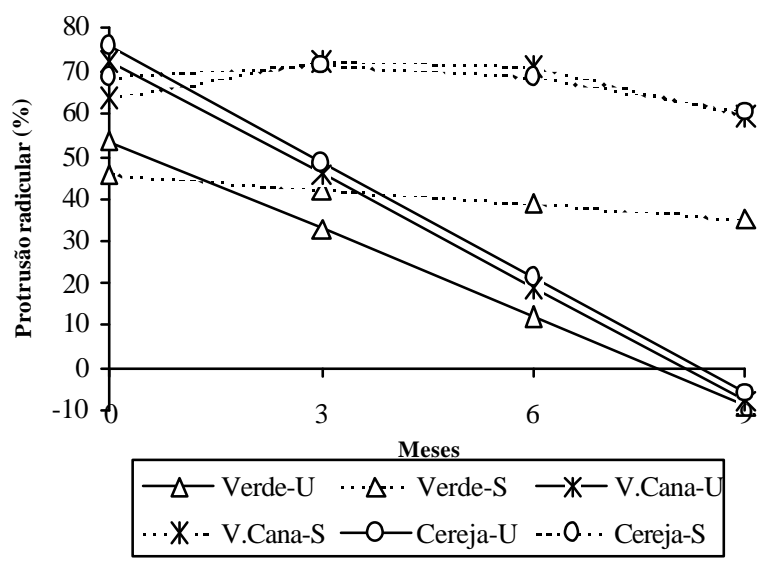

$\begin{array}{llll}\text { yvu }=62,7277-8,06282 x & r^{2}=0,8982 & \text { yvcs }=77,2471+1,53054 x-0,36966 x^{2} & r^{2}=0,9895 \\ \text { yvs }=51,5066-1,62255 x & r^{2}=0,7926 & \text { ycu }=86,3894-10,48435 x & r^{2}=0,8043\end{array}$ $\mathrm{yvcu}=79,0223-9,65711 \mathrm{x} \quad \mathrm{r}^{2}=0,8273 \quad \mathrm{ycs}=79,4108-1,79898 \mathrm{x} \quad \mathrm{r}^{2}=0,9571$

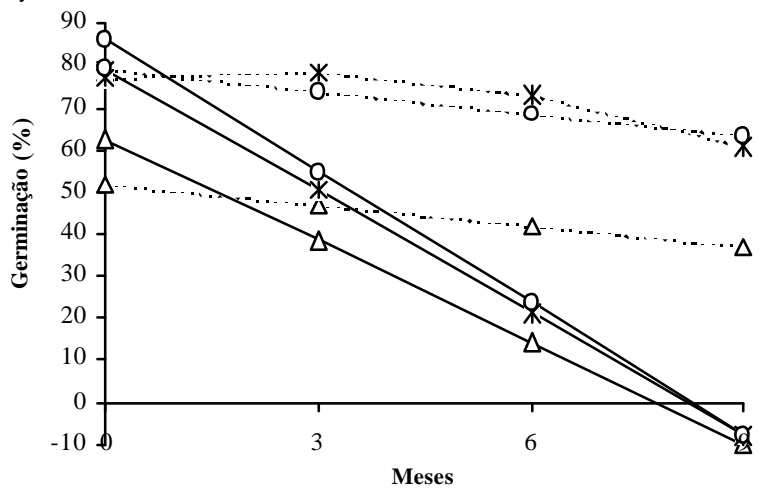

FIG. 4. Efeito da secagem na protrusão de radículas (15 dias) e na percentagem de germinação (30 dias) de sementes de cafeeiro, colhidas nos estádios verde, verde cana e cereja, em função do armazenamento por diferentes períodos.

colhidas no estádio verde apresentaram-se com qualidade fisiológica inferior às colhidas no estádio verde cana e cereja ao longo dos nove meses de armazenamento.

Pode-se, ainda, observar pelas Figuras 4 a 6, que sementes secadas para teores de água próximos a $15 \%$ tiveram sua qualidade fisiológica preservada satisfatoriamente ao longo dos nove meses de armazenamento sob condições de $10^{\circ} \mathrm{Ce}$ 50\% UR, independente do estádio de desenvolvimento das sementes. Araújo et al. (1989) verificaram efeito deletério sobre a germinação e o vigor de sementes secadas a $30^{\circ} \mathrm{C}$ para um teor de água de $11,90 \%$, após seis meses de armazenamento sob condições de ambiente de laboratório. Para as sementes colhidas no estádio verde cana e secadas,

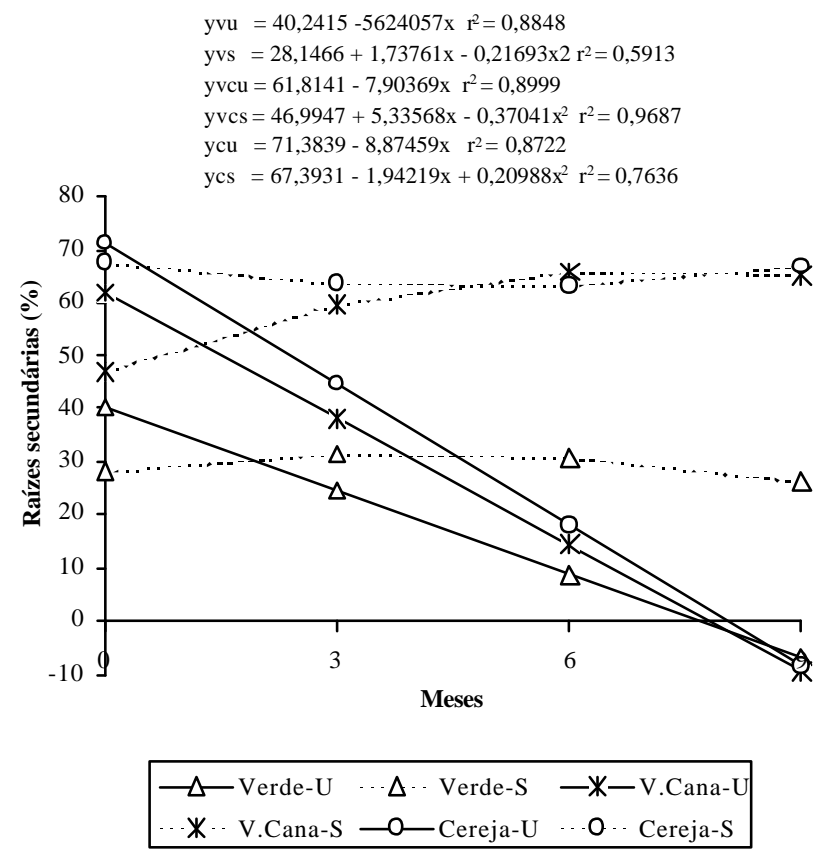

FIG. 5. Efeito da secagem na emissão de raízes secundária (30 dias) de sementes de cafeeiro, colhidas nos estádios verde, verde cana e cereja, em função do armazenamento por diferentes períodos.

verifica-se, pelas Figuras 4 e 5 que após três meses de armazenamento, ocorreu um incremento da protrusão radicular, germinação, emissão de raízes secundária e índice de velocidade de emergência. Isto pode ter ocorrido em função de obtenção de dormência pelas sementes não armazenadas. Pode-se ainda verificar, pela Figura 4, tendência de superioridade em termos de percentagem de protrusão radicular e germinação das sementes colhidas no estádio verde cana a partir de três meses de armazenamento. Quanto à emissão de raízes secundárias, verifica-se pela Figura 3, que as sementes colhidas nos estádios verde e verde cana apresentaram quedas significativas, logo após a secagem das sementes, ao passo que, para aquelas colhidas no estádio verde cana, a redução foi em torno de $30 \% \log$ o após a secagem, mostrando-se intolerantes à dessecação. No entanto, as sementes colhidas no estádio verde cana apresentaram um incremento nessa característica ao longo do armazenamento (Figura 5), chegando, após seis meses de armazenamento, a superar as sementes colhidas no estádio cereja. Possivelmente, com a secagem, as sementes colhidas no estádio verde cana foram induzidas a um estado de dormência, provavelmente pela presença de inibidores à germinação como, por exemplo, ácido abscísico (Leprince et al., 1993) ou resistência de tecidos que circundam o embrião (Bewley et al., 1989; Berry \& Bewley, 1991) 

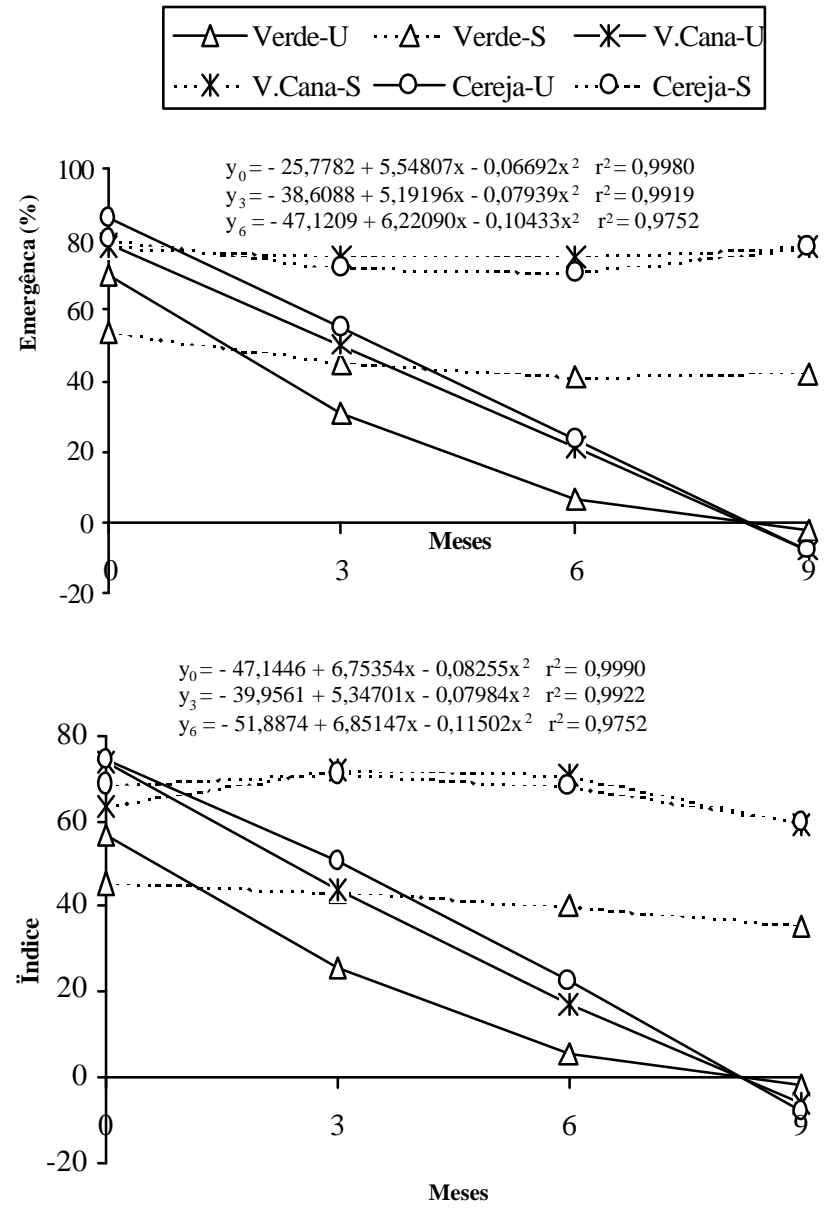

FIG. 6. Efeito da secagem na percentagem de emergência e índice de velocidade de emergência de sementes de cafeeiro, colhidas nos estádios verde, verde cana e cereja em função do armazenamento por diferentes períodos.

que podem inibir a germinação e, por isso, confundir os efeitos degenerativos da secagem (Guimarães, 2000). Ellis et al. (1991) verificaram que sementes de cultivares de Coffea arabica colhidas no estádio verde cana (maturidade intermediária), apresentaram-se mais tolerantes a uma dessecação de até 4-5\% de umidade do que as de frutos maduros ou imaturos.

\section{CONCLUSÕES}

2Sementes de cafeeiro apresentam aumento do nível de tolerância à dessecação com o aumento do estádio de desenvolvimento, ao passo que sementes colhidas no estádio verde apresentam maior sensibilidade à dessecação.

Sementes de cafeeiro secadas a $15 \%$ de umidade, utilizando $30^{\circ} \mathrm{C}$, têm sua viabilidade e vigor reduzidos nos diferentes estádios de desenvolvimento.
ES Sementes secadas a 15\% de umidade mantêm a qualidade fisiológica ao longo de nove meses de armazenamento sob condições de $10^{\circ} \mathrm{C}$ e $50 \%$ de UR, em embalagem hermética. ESementes não secadas (50\% de umidade) apresentam queda linear na qualidade fisiológica ao longo do armazenamento sob condições de $10^{\circ} \mathrm{C}, 50 \%$ UR e embalagem hermética.

\section{REFERÊNCIAS}

ARAÚJO, E.F.; CORRÊA, P.C.; PEREIRA, O.A. Influência da temperatura de secagem na germinação de sementes de café. Revista Brasileira de Sementes, Brasília, v.11, n.1,2,3, p.69-75, 1989.

BERRY, T.; BEWLEY, J.D. Seeds of tomato (Lycoperiscon esculentum Mill) which develop in a fully hydrated environment in the fruit switch from a developmental to a germinative mode without a requirement for desiccation. Planta, Berlim, v.186, n.1, p.27-34, 1991.

BEWLEY, J.D.; BLACK, M. Seeds : physiology of development and germination. New York: Plenum Press, 1985. 367p.

BEWLEY, J.D.; KERMODE, A.R.; MISRA, S. Desiccation and minimal drying treatments of seeds of castor bean and Phaseolus vulgaris which terminate development and promote germination cause changes in protein and messenger RNA synthesis. Annalsof Botany, New York, v.63, n.1, p.3-17, 1989.

BOCHICCHIO A.; VERNIERI, P.; PULIGA, S. BALDUCCI, F.; VAZZANA, C. Acquisition of desiccation tolerance by isolated maize embryos exposed to different conditions: the questionable role of endogenous abscisic acid. Physiologia Plantarum, Copenhagem, v.91, n.4, p.615-622, 1994.

BOCHICCHIO, A.; VERNIERI, P.; PULIGA, S.; MURELLI, C.; VAZZANA, C. Desiccation tolerance in immature embryos of maize: sucrose, raffinose and the ABA-sucrose relation. In: ELLIS, R.H.; BLACK, M.; MURDOCH, A.J.; HONG, T.D.(Ed.). Basic and applied aspects of seed biology. Dordrecht: Kluwer Academic, 1997. p.13-22 (Current Plant Sciences and Biotechnology in Agriculture, 30). Proceedings of the Fifth International Workshop on Seeds, Reading, 1995.

BOCHICCHIO, A.; VERNIERI, P.; PULIGA, S.; VELASCO, R.; VAZZANA, C.; COME, D.; CORBINEAU, F. Desiccation tolerance in immature embryos of maize: possible implication of ABA. In: INTERNATIONAL WORKSHOP ON SEEDS: basic and applied aspects of seed biology, 4., 1992, Angers, France, Proceedings... Angeres, 1993, v.1, p.115-120.

BRASIL, Ministério da Agricultura e da Reforma. Regras para análise de sementes. Brasília: SNDA/DNDV/CLAV, 1992. 365p.

BRENAC, P.; HORBOWICZ, M.; DOWNER, S.M.; DICKERMAN, A.M.; SMITH, M.E. ; OBENDORF, R.L. Raffinose accumulation related to desiccation tolerance during maize (Zeamays L.) seed development and maturation. Journal of Plant Physiology, Stuttgart, 1997. (in press).

CARVAlHO, M. M. de ; ALVARENGA, G. Determinação do estádio de desenvolvimento mínimo do fruto do cafeeiro (Coffea arabica L.), para germinação. In: CONGRESSO BRASILEIRO DE 
PESQUISAS CAFEEIRAS, 7., 1979, Araxá. Resumos... Rio de Janeiro: I.B.C./GERCA, 1979. p.118-119.

CHIN, H.F., Recalcitrant seeds: a status report. Rome: International Board for Plant Genetic Resources, 1988. 28p.

COPELAND, L.O.; McDONALD, M.B.Principles of seed science and technology. 3. ed. Boston: KAP, 1995. 409p.

ELLIS, R.H.; HONG, T.D. ; ROBERTS, E. H. An intermediate category of seed storage behaviour?: I. Coffee. Journal of Experimental Botany, Oxford, v.41, n.230, p.1167-1174, 1990.

ELLIS, R.H.; HONG, T.D. ; ROBERTS, E. H. An intermediate category of seed storage behaviour?: II. Effects of provenance. Journal of Experimental Botany, Oxford, v.42, n.238, p.653-657, 1991.

GUIMARÃES, R.M. Tolerância à dessecação e condicionamento fisiológico em sementes de cafeeiro (Coffea arabica, L.). 2000. 180f. Tese ( Doutorado em Fitotecnia) - Universidade Federal de Lavras, Lavras.
KING, M.W.; ROBERTS, E.H. The storage of recalcitrant seeds: achievements and possible approaches. Rome: International Board for Plant Genetic Resources, 1979. 96p.

LEPRINCE, O.; HENDRY, G.A.F.; McKERSIE, B.D. The mechanisms of desiccation tolerance in developing seeds. Seed Science Research, Wallingford, v.3, p.231-246. 1993.

MAGUIRRE, J.D. Speed of germination - aid seedling emergence and vigor. Crop Science, Madison, v.2, p.176-177, 1962.

PRIESTLEY, D.A. Seed ageing: implications of seed storage and persistence in the soil. Ithaca: Cornell University Press, 1986. 304 p.

ROBERTS, E. H.; KING, W.W.; ELLIS, R.H. Recalcitrant seeds, their recognition and storage. In: HOLDEN, J.H.W.; WILLIANS, J.T. (Ed.). Crop genetic resources: conservation and evolution. London: Allen and Unwin, 1984. p.38-52.

ROBERTS, E. H. Predicting the storage life of seeds. Seed Science and Technology, Zurich, v.1,n.3, p.499-514, 1973. 